\title{
How far, how long: On the temporal scope of prosodic boundary effects ${ }^{\text {a) }}$
}

\author{
Dani Byrd, ${ }^{\text {b) }}$ Jelena Krivokapić, and Sungbok Lee ${ }^{\text {c) }}$ \\ USC Department of Linguistics, University of Southern California, 3601 Water Way, GFS 301, \\ Los Angeles, California 90089-1693
}

(Received 16 February 2005; revised 30 May 2006; accepted 1 June 2006)

\begin{abstract}
Acoustic lengthening at prosodic boundaries is well explored, and the articulatory bases for this lengthening are becoming better understood. However, the temporal scope of prosodic boundary effects has not been examined in the articulatory domain. The few acoustic studies examining the distribution of lengthening indicate that boundary effects extend from one to three syllables before the boundary, and that effects diminish as distance from the boundary increases. This diminishment is consistent with the $\pi$-gesture model of prosodic influence [Byrd and Saltzman, J. Phonetics 31, 149-180 (2003)]. The present experiment tests the preboundary and postboundary scope of articulatory lengthening at an intonational phrase boundary. Movement-tracking data are used to evaluate durations of consonant closing and opening movements, acceleration durations, and consonant spatial magnitude. Results indicate that prosodic boundary effects exist locally near the phrase boundary in both directions, diminishing in magnitude more remotely for those subjects who exhibit extended effects. Small postboundary effects that are compensatory in direction are also observed. (C) 2006 Acoustical Society of America. [DOI: 10.1121/1.2217135]
\end{abstract}

PACS number(s): 43.70.Bk [AL]

Pages: 1589-1599

\section{INTRODUCTION}

\section{A. Articulatory studies on phrase boundary effects}

Prosodic structure shapes the production of individual phonological units at phrase boundaries and under accent. In the vicinity of prosodic boundaries, segments exhibit acoustic final lengthening (e.g. Oller, 1973; Klatt, 1976; Wightman et al., 1992) and initial lengthening (Oller, 1973). Articulatory studies show that at phrase edges "gestures get larger, longer, and further apart" (Byrd and Saltzman, 2003, p. 159; Byrd et al., 2000). Articulations are spatially more extreme and temporally longer (Edwards et al., 1991; Beckman and Edwards, 1992; Fougeron and Keating, 1997; Byrd and Salzman, 1998; Fougeron, 2001; Cho, 2006; Cho and Jun, 2000; Cho and Keating, 2001; Tabain, 2003; Keating et al., 2004; Tabain and Perrier, 2005).

Phrase final and initial articulatory lengthening have been observed to increase cumulatively for larger prosodic boundaries (phrase finally: Byrd and Saltzman, 1998; Byrd, 2000; Cho, 2006; Tabain, 2003; Tabain and Perrier, 2005; and phrase initially: Byrd and Saltzman, 1998; Cho and Keating, 2001; Fougeron, 2001; Cho, 2006; Tabain, 2003; Keating et al., 2004), though there is individual variation. Articulatory studies have also shown there to be less temporal overlap between articulations separated by a boundary or adjacent to a boundary (McClean, 1973; Byrd et al., 2000;

\footnotetext{
a) Portions of this work were presented in "On the temporal scope of boundary effects in articulation" Acoustical Society of America meeting, San Diego, California, November 2004.

b) Author to whom correspondence should be addressed; electronic mail: dbyrd@usc.edu

c) Also at: University of Southern California, Viterbi School of Engineering, Los Angeles, CA 90089.
}

Byrd and Saltzman, 1998; Byrd, 2000; see also Hacopian, 2003). This depends on boundary strength; gestures are less overlapped across stronger boundaries (Byrd, 2000; Cho, 2004).

In the spatial domain, Fougeron and Keating (1997) and others show the effects of increased linguapalatal contact to be cumulative-higher (stronger) prosodic boundaries induce greater linguapalatal contact, both phrase initially (Fougeron and Keating, 1997; Cho and Keating, 2001; Fougeron, 2001; Keating et al., 1999; Tabain, 2003; Keating et al., 2004) and phrase finally (Fougeron and Keating, 1997 [although their results are less consistent across speakers than their results for phrase-initial effects], Keating et al., 1999; see also Hacopian, 2003; Tabain, 2003). Both phrasefinal and phrase-initial magnitude results tend to vary across speakers and across segments examined (see, e.g., Byrd et $a l ., 2005)$, and different studies find spatial effects at different prosodic domains.

\section{B. Acoustic and articulatory studies on the temporal scope of phrase boundary effects}

While the articulatory and acoustic effects of boundaries have been examined in a number of studies, the temporal scope of boundary effects-i.e., the interval preceding and following a boundary over which they occur-has been far less studied. A few studies have addressed this question in the domain of acoustics. Oller (1973) examined onset and coda lengthening and found that generally both lengthen in final syllables. Berkovits (1993a, 1993b) showed that in phrase-final bisyllabic words with stress on the second (final) syllable, lengthening of segments within the final syllable is largest in the final segment and decreases in the preceding segments. Furthermore, phrase-final lengthening extends to 
the initial syllable (of bisyllabic words) but is lesser in magnitude than in the final syllable. Berkovits (1994) examined lengthening of phrase-final bisyllabic words with initial and final stress and found that words with initial stress show lengthening on both the initial and the final syllable and again, that the lengthening in the segments of the final syllable increases progressively closer towards the boundary. Words with final stress in this experiment show lengthening only on the final syllable, and again, segmental lengthening increases progressively towards the boundary. Overall, the initial syllable of two-syllable words lengthens less than the final syllable, and lengthening is mainly on the final syllable (Berkovits, 1993b, 1994).

Shattuck-Hufnagel and Turk (1998) examined lengthening effects, and they showed preboundary lengthening beyond the final syllable, back to the stressed syllable of a word. Lengthening is strongest in the final syllable. The postboundary effects show more lengthening on the onset than the rime vowel, which does not appear to lengthen. Turk (1999) reported that two-syllable words show phrase final lengthening back to the rime of the stressed syllable. Significant lengthening mainly occurs on the rimes, not on the onsets. (In the case of words with stress on the second syllable, one of two subjects showed a significant shortening effect on the rime of the first syllable.) Lengthening in the final syllable increases from nucleus to coda.

Cambier-Langeveld (1997), in her acoustic study on Dutch, examined the preboundary extent of the effect of prosodic boundaries. She found that the lengthening is largest in the final segment, and decreases in the preceding ones. Generally, the lengthening domain is the final syllable, but significant lengthening on the nucleus of the penultimate syllable occurred in one token word (mode), whose last syllable consists of an onset and a reduced vowel. (A trend for lengthening of the penultimate nucleus also occurred in the word tandem, in which the vowel of the final syllable is also reduced.) As Cambier-Langeveld noted, the effect of syllable weight on the domain of final lengthening could be explained by the fact that these syllables are phonetically shorter than the syllables with an unreduced vowel. Finally, CambierLangeveld pointed out that even though the amount of lengthening increases with higher prosodic boundaries, the domain of lengthening does not become larger. This result is similar to Berkovits's findings, who reported that, in words with initial stress, the first syllable accounts for $25 \%$ of the lengthening, the final syllable for $75 \%$. In words with final stress, $5 \%$ of the average lengthening was due to the initial syllable and 95\% was due to the lengthening of the final syllable (Berkovits 1993a, 1994). The figures in Turk (1999) point to a similar distribution of lengthening.

In the articulatory domain, there are only a few studies that tangentially examine the temporal extent or scope of phrasal lengthening. Byrd and Saltzman (1998) compared opening movements for $\mathrm{C}_{1}$ and closing movements for $\mathrm{C}_{2}$ in $\left[\mathrm{C}_{1} \mathrm{~V}_{1} \# \mathrm{C}_{2} \mathrm{~V}_{2}\right]$ sequences and show that the postboundary temporal effect is stronger. Byrd (2000) reported that, in $\left[\mathrm{C}_{1} \mathrm{~V}_{1} \# \mathrm{C}_{2} \mathrm{~V}_{2}\right]$ sequences, $\mathrm{V}_{1}$ exhibits longer articulatory duration than $\mathrm{V}_{2}$. A further indication of progressive final lengthening is evident in the results of Edwards et al. (1991) and Beckman and Edwards (1992). They examined jaw movement in a $\mathrm{VC}$ sequence phrase finally and found that there is an increase in duration of the jaw opening and jaw closing movements, and that the effects are more prominent in the final jaw closing. Fougeron and Keating (1997) examined palatal contact in $\left[\mathrm{n}_{1} \mathrm{O}_{1} \# \mathrm{n}_{2} \mathrm{O}_{2}\right]$ sequences. They found for the consonants that there is a boundary effect not just domain initially $\left(\mathrm{n}_{2}\right)$, but also in some cases domain finally $\left(\mathrm{n}_{1}\right)$; however, the effect is much stronger closer to the boundary (that is, for $\mathrm{n}_{2}$ ). Similarly for the vowel, the boundary effect was much stronger for the vowel closer to the boundary $\left(\mathrm{o}_{1}\right)$ than for the vowel farther away from the boundary $\left(\mathrm{o}_{2}\right)$. Their results can be taken to indicate a progressively decreasing effect of the phrase boundary (see also, Gendrot, 2005).

Together, the acoustic and articulatory studies point to decreased lengthening with distance from a phrasal boundary. Absolute phase final segments lengthen more than preceding ones. Furthermore, even though the degree of lengthening is a function of boundary type, the temporal locale of lengthening seems often to be largely, though not entirely, limited to the boundary-adjacent segments. Articulatory studies addressing the temporal scope of the boundary effects are sparse.

\section{The $\pi$-gesture framework}

Findings as to the temporal scope of phrasal effects on articulations have theoretical implications for the prosodic gesture ( $\pi$-gesture) framework of Byrd and Saltzman (Byrd and Saltzman, 2003; Byrd et al., 2000; Byrd, 2000). The $\pi$-gesture model extends the notion of phonological units being defined as intrinsically temporal (e.g., Browman and Goldstein, 1992), by viewing prosodic events such as phrase boundaries as having a temporal interval of activation, similar to constriction gestures. Many of the phrasal effects of longer duration, greater magnitudes, and decreased intergestural overlap have been successfully captured by simulations of boundaries, implemented as $\pi$-gestures, interacting with articulatory gestures within this model (Byrd and Saltzman, 2003). In this simulation work, a $\pi$-gesture on the prosodic tier influences all constriction gestures that are concurrently active with it. This overlap among suprasegmental and constriction gestures is shown in Fig. 1.

During the activation of a phrasal $\pi$-gesture, the central clock controlling the rate of activation-unfolding for active gestures is slowed (Byrd and Saltzman, 2003). The amount of slowing down depends on the strength of activation of the $\pi$-gesture, which is a reflection of the strength of the prosodic boundary. Because the $\pi$-gesture has a temporally discrete and smoothly varying interval of activation, the $\pi$-gesture model predicts that boundary effects should be local, that is, not discontinuous (Byrd and Saltzman, 2003). Further, because the $\pi$-gesture waxes and wanes in activation, the lengthening associated with a $\pi$-gesture is predicted to likewise increase in degree as the $\pi$-gesture's peak activation is reached and then decrease (Byrd and Saltzman, 2003). ${ }^{1}$ 


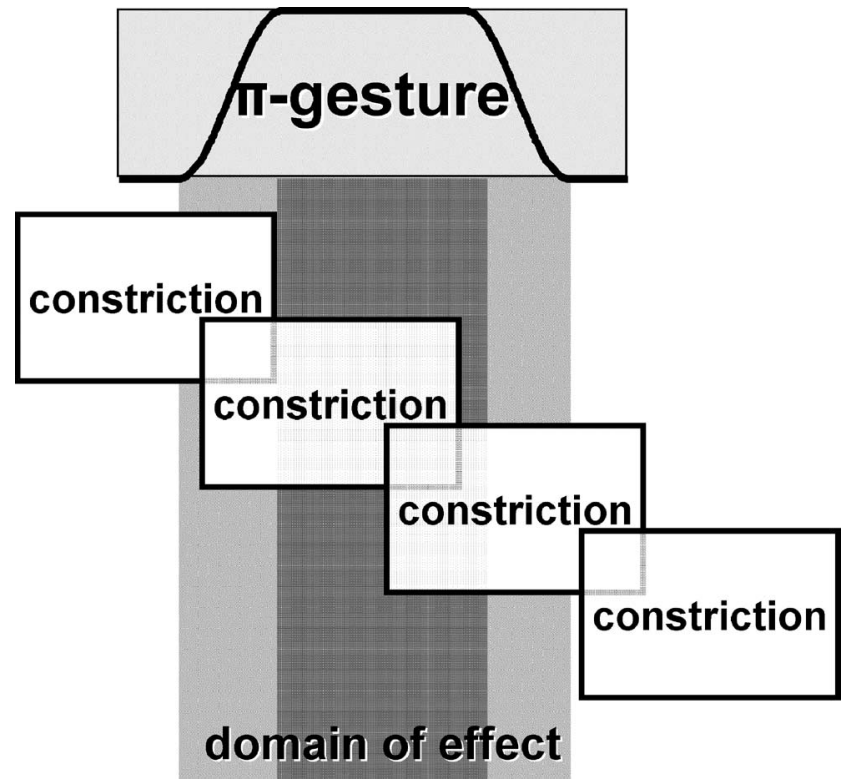

FIG. 1. A schema of the $\pi$-gesture model representing the overlap of a $\pi$-gesture at a phrasal juncture with several closing movement gestures. Shading darkness represents strength of the $\pi$-gesture effect as the $\pi$-gesture's activation increases to maximum (darkest shading). The constriction gestures are representative of any consonant or vowel. In our experiment, the constrictions potentially represent the consonants N D D N.

\section{Goals of the present study}

The primary goal of this study is an empirical one-that is, to investigate the temporal scope of prosodic lengthening in the articulatory domain, since such articulatory data are not currently available in the literature. This articulatory kinematic experiment explicitly investigates the preboundary and postboundary extent of phrasal effects in the articulatory domain. Based on the results from the acoustic studies, we expect that the strongest articulatory lengthening will appear near the phrase edge but that lengthening could also be possible more remotely. We also seek to add to the description of the general nature of prosodically-driven temporal perturbation to articulation. We report spatial magnitude effects as well, primarily for the purpose of determining if they mirror the temporal effects observed for the vertical tongue tip movement, i.e., the tongue tip $y$ trajectories (and, of course, for the purpose of adding to the limited data in the kinematic literature on phrasal spatial effects). We do not evaluate these spatial results in a theoretical context here.

We also pursue the additional secondary goal of evalu-

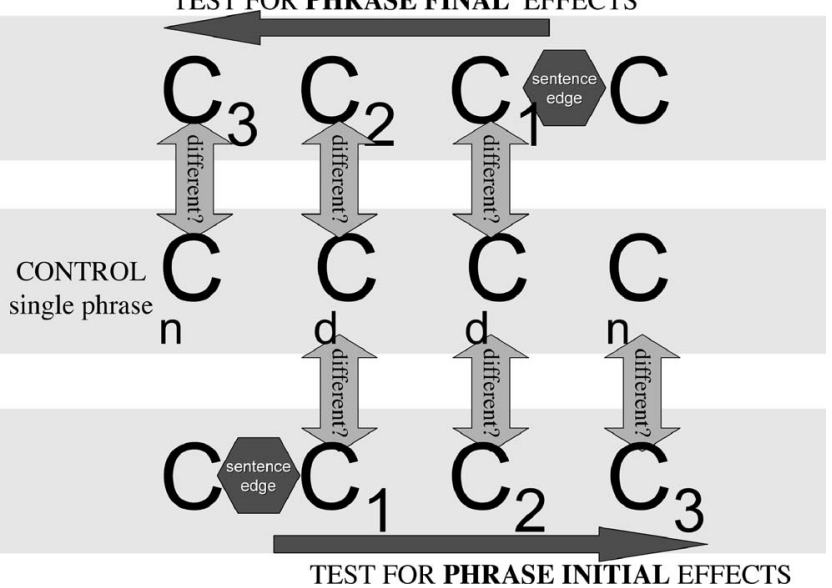

FIG. 2. Schematized experimental design.

ating whether the pattern of results is consistent with the $\pi$-gesture model of Byrd and Saltzman (2003). Because a $\pi$-gesture has a temporally discrete interval of activation with a smoothly waxing and waning function, it would be expected that boundary effects should be local to the boundary and not discontinuous (Byrd and Saltzman, 2003). Further, because the $\pi$-gesture waxes and wanes in activation, the degree of lengthening associated with a $\pi$-gesture is likewise expected to increase (as the $\pi$-gesture's peak activation is reached) and then decrease (Byrd and Saltzman, 2003). Lastly, prosodically driven lengthening is expected to be generally symmetrical [this is not a requirement of the model, merely the null hypothesis adopted in Byrd and Saltzman (2003)].

\section{METHOD}

\section{A. Stimuli and subjects}

Three stimuli, given in Table I, were used to test phrase boundary effects on preboundary and postboundary sequences of consonants, with the same phonological string appearing in each. The target sequence in each utterance was $[\ldots . . n V d V d V n V . .$.$] . The articulation of the tongue tip conso-$ nants will be investigated using articulatory movement tracking of a transducer placed on the tongue tip. For ease of presentation, we will denote the target sequence as $[\mathrm{N} \mathrm{D} \mathrm{D}$ $\mathrm{N}]$.

In order to avoid any confounding effect of accent at the phrase boundary, subjects were asked to emphasize (place in

TABLE I. Stimulus 1 is testing for preboundary effects; the consonants to be measured are N D D. Stimulus 2 is testing for postboundary effects; the consonants to be measured are D D N. Stimulus 3 is the control utterance and contains a phrase-medial sequence of consonants. (Subjects were instructed to emphasize the underlined word to control somewhat for focal accent placement.)

\begin{tabular}{|c|c|c|}
\hline Effect & Consonants & Sentence \\
\hline Preboundary effects & N D D & $\begin{array}{l}\text { Birdhunting, we were shocked to see a new dodo. } \\
\text { Knock on wood that there are more. }\end{array}$ \\
\hline Postboundary effects & D D N & $\begin{array}{l}\text { At the zoo, we were shocked to see a Gnu. Dodo } \\
\text { knocking about, however, would have been more } \\
\text { surprising. }\end{array}$ \\
\hline Control & N D D N & $\begin{array}{l}\text { Birdhunting, we were shocked to see a new dodo } \\
\text { knocking on wooden posts. }\end{array}$ \\
\hline
\end{tabular}


focus) the underlined words ("shocked" and "more"), thus ensuring that the words containing the experimental target consonants did not receive a tonic accent. Sentence 1 probes for preboundary effects using the consonants (N D D). These consonants are compared to the parallel consonants in the control sentence (Sentence 3) in which the sequence is entirely phrase medial. Sentence 2 probes for postboundary effects using the consonants (D D N). They are likewise compared to the parallel phrase-medial consonants in the control utterance. The experimental design is schematized in Fig. 2. It should be noted that the preboundary consonant is not immediately before the boundary but is rather the onset consonant of the preboundary syllable; unlike the postboundary onset consonant, which is absolutely phrase-initial.

Four subjects, all native speakers of American English with no known speech or hearing disorders, participated. Subjects will be referred to as Subject A, Subject D (the first author), Subject E, and Subject J. The stimuli were pseudorandomized in blocks of three stimuli with no adjacent identical tokens. Subjects read each utterance 12 times and were instructed to read in a casual conversational style. (For Speaker D, 3 of the 36 tokens [ 1 control and 2 postboundary] were lost due to data collection error.)

The audio recordings were evaluated using ToBI guidelines (Beckman and Elam, 1997). They were realized with the expected intonation: The utterance testing the postboundary effect was realized with an intonation phrase boundary (marked by a boundary tone and a break index 4) after the word "Gnu." The utterance testing the preboundary effect was realized with an intonation phrase boundary (marked by a boundary tone and a break index 4) after the word "dodo." The control utterance was realized as one or as two intonation phrases ("birdhunting" was sometimes realized as a separate intonation phrase)—but, crucially, the relevant consonants under examination were all within one intonation phrase. Thus, we confirm that the experiment will be able to test the effects of the presence of an intonational phrase boundary on the consonant sequence using the no-boundary sentence as a control.

\section{B. Data collection}

The Carstens Articulograph (AG200) was used to track a sensor adhered to the tongue tip. (For a subset of the subjects, a tongue dorsum sensor was adhered as well, though it was irrelevant for the analysis design of this study.) Reference sensors were tracked on the maxilla and bridge of the nose and a sample of the occlusal plane of each subject was acquired. Articulatory data were sampled at $200 \mathrm{~Hz}$, and acoustic data at $16 \mathrm{kHz}$. After data collection, data were corrected for head movement and rotated to the occlusal plane. The tongue tip $y$ (vertical) signal was differentiated, and signals were smoothed before and after differentiation with a ninth-order Butterworth filter of cutoff frequency $15 \mathrm{~Hz}$. [For all speakers' tongue tip constrictions, the $x$ (horizontal) component of the movement was negligible; the consonants were dominantly formed in the vertical direction.]

\section{Data analysis}

For each of the consonants to be analyzed (N D D for the preboundary effects, D D N for the postboundary effects, and $\mathrm{N}$ D D N for the control condition), three timepoints were defined: The onset of the closing movement, the closing movement extremum (also initiation of consonant opening movement), and the end of the opening movement. These timepoints were defined by zero-crossings in the tongue tip velocity trajectory (For the last consonant $([\mathrm{n}])$ in all conditions, the endpoint of opening movement could not be reliably identified and is not analyzed.) By definition, the end of opening movement for consonant one is also the onset of closing movement for consonant two, etc.; that is, a total of eight timepoints were identified. There were cases where there were two zero-crossings for the tongue tip extremum for a consonant - the first consonant ([n]) across all sentences and the second consonant [d] in the [N \# D D N] sentence-in these cases, the spatially highest peak was selected to designate the extremum point. Further, at the boundary, there were cases for subjects $\mathrm{A}, \mathrm{J}$, and $\mathrm{E}$ in which there were multiple zero-crossings at the end of the preboundary consonant opening, defining both the end of the opening movement and simultaneously the beginning of the closing movement. The zero-crossing selected for this point was that which was temporally closest to the highest peak velocity of the upcoming postboundary consonant.

Additionally, the spatial position of the tongue tip $y$ trajectory was measured at each of these timepoints. Finally, for each closing and opening movement, the time of peak velocity was also measured, yielding an additional eight timepoints. In the case of preboundary [d] opening and postboundary [n] closing, multiple velocity peaks sometimes occurred, and in such cases, the fastest peak was chosen. Thirteen atypical tokens were excluded from the analysis.

For each consonant's closing movement and opening movement, the following dependent variables were derived from the measured timepoints of the tongue tip vertical $(y)$ transducer:

1 Duration:

- For closing movement: Time from onset of closing movement to extremum.

- For opening movement: Time from extremum to end of opening movement.

2 Time-to-peak-velocity:

- For closing movement: Time from onset of closing movement to peak closing velocity.

- For opening movement: Time from onset of opening movement to peak opening velocity.

3 Extremum position (one tongue tip y extremum for each [n], [d], [d], and [n]).

4 Displacement:

- For closing movement: Euclidean distance between position at closing movement onset and at extremum.

- For opening movement: Euclidean distance between position at extremum and at end of opening movement.

These kinematic landmarks and derived variables are 


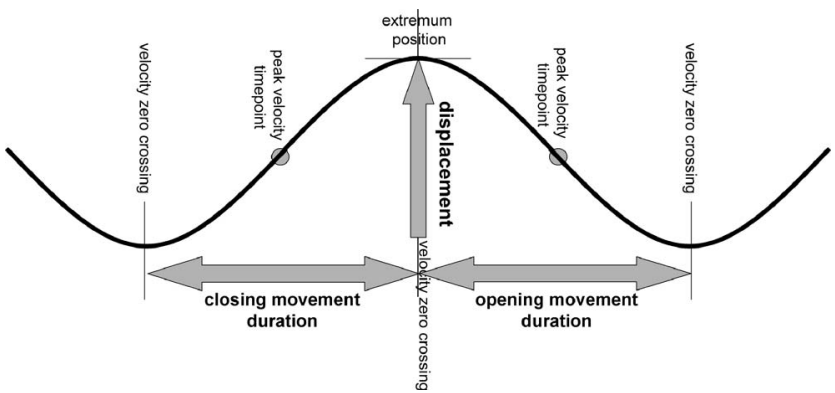

schematized in Figure 3 for a single consonant (note that displacement can potentially be affected by either or both onset and offset position). Time-to-peak-velocity has proven to be a good indicator of gestural stiffness within a massspring gestural model as modeled within Task Dynamics (Saltzman and Munhall, 1989) and similar models of movement control, i.e., the parameter shaping the internal temporal properties of an articulatory gesture. Stiffness is the primary control parameter that has been implicated in phrasal lengthening (e.g., Edwards et al., 1991; Beckman and Edwards, 1992; Byrd et al., 2000) and a slowed gating-in of target stiffness is one of the consequences of clock slowing within the $\pi$-gesture model (Byrd and Saltzman, 2003).

Two-tailed $t$-tests were conducted testing the preboundary and postboundary effect on duration, time-to-peakvelocity, extremum position, and displacement. Criterial significance was set at $p<0.05$. All and only statistically significant results are reported.

\section{RESULTS}

In presenting the details of temporal scope of effect, it will be convenient to numerically designate the consonant position relative to the utterance edge. To do this, we will use the designation $\mathrm{C} 1$ to refer to the consonant that is either the final (for the preboundary condition) or initial (for the post-
FIG. 3. Schema of the measured points in the tongue tip vertical $(y)$ trajectory. boundary condition) consonant in the test utterance, $\mathrm{C} 2$ to refer to the next-most preceding/following consonant, etc. Recall, however, that the while the postboundary $\mathrm{C} 1$ is immediately following the boundary, the preboundary $\mathrm{C} 1$ is the onset consonant of the preboundary syllable and thus not immediately at the final phrase edge.

Regarding acoustic pauses at the boundary, Speakers A, $\mathrm{E}$, and J's pauses (i.e., silences) in the preboundary test utterance range from 350 to $650 \mathrm{~ms}$; while for Speaker D's, only three were longer than $200 \mathrm{~ms}$ (the longest at $350 \mathrm{~ms}$ ). Speakers A, E, and J's pauses (i.e., silences) in the postboundary test utterance range from 200 to $970 \mathrm{~ms}$; while for Speaker D's, only four were longer than $200 \mathrm{~ms}$ (the longest at $350 \mathrm{~ms}$ ), as with her preboundary condition sentence. In the preboundary condition, Speakers A, E, and J place the end of the opening movement for preboundary $\mathrm{C} 1$ in the second half of the acoustic pause; whereas for speaker D, this movement ends in all but one case during the vowel. Likewise, in the postboundary condition, Speakers A, E, and $\mathrm{J}$ place the beginning of the closing movement for postboundary $\mathrm{C} 1$ in the second half of the acoustic pause; whereas for speaker D, this movement starts during the preboundary vowel).

Another point to consider is that while this study explicitly controls for tonic accent, the possibility of variation in

TABLE II. Preboundary temporal scope of effect on C1: $t$-test results and means (SD) (ms). The reported $n$ is the total number of tokens in the test plus the control conditions.

\begin{tabular}{|c|c|c|c|c|}
\hline \multicolumn{5}{|c|}{ Preboundary temporal scope of effect on $\mathrm{C} 1$ : C3 C2 C1] } \\
\hline & $\begin{array}{c}\mathrm{C} 1 \text { closing } \\
\text { movement duration }\end{array}$ & $\begin{array}{c}\text { C1 closing } \\
\text { movement time-to- } \\
\text { peak-velocity }\end{array}$ & $\begin{array}{c}\mathrm{C} 1 \text { opening movement } \\
\text { duration }\end{array}$ & $\begin{array}{l}\mathrm{C} 1 \text { opening movement } \\
\text { time-to-peak-velocity }\end{array}$ \\
\hline Subject & n.s. & n.s. & $t=15.351, p<0.0001$ & $t=3.959, p=0.0007$ \\
\hline A & Control: 76 (5) & Control: 45 (4) & Control: 86 (13) & Control: $31(3)$ \\
\hline$n=24$ & Test: $79(5)$ & Test: 48 (4) & Test: $564(107)$ & Test: $36(3)$ \\
\hline Subject & $t=4.120, p=0.0006$ & $t=2.462, p=0.0235$ & $t=2.445, p=0.0244$ & n.s. \\
\hline D & Control: 98 (7) & Control: 56 (7) & $\mathrm{n}=20$ & Control: 45 (8) \\
\hline \multirow[t]{2}{*}{$n=21$} & Test: $113(9)$ & Test: $65(8)$ & Control: $82(6)$ & Test: 49 (6) \\
\hline & & & Test: 143 (83) & \\
\hline Subject & n.s. & n.s. & $t=19.268, p<0.0001$ & n.s. \\
\hline $\mathrm{E}$ & Control: 88 (7) & Control: 55 (9) & Control: $96(10)$ & Control: 40 (5) \\
\hline$n=23$ & Test: $86(2)$ & Test: $52(3)$ & Test: $560(79)$ & Test: $41(8)$ \\
\hline Subject & n.s. & n.s. & $t=8.634, p<0.0001$ & $t=6.288, p<0.0001$ \\
\hline $\mathrm{J}$ & Control: 69 (2) & Control: 36 (2) & Control: $62(8)$ & Control: 32 (3) \\
\hline$n=18$ & Test: 69 (3) & Test: 37 (3) & Test: 396 (116) & Test: 41 (3) \\
\hline
\end{tabular}


TABLE III. Postboundary temporal scope of effects on C1 $t$-test results and means (SD) (ms). The reported $n$ is the total number of tokens in the test plus the control conditions.

\begin{tabular}{|c|c|c|c|c|}
\hline \multicolumn{5}{|c|}{ Post-boundary temporal scope of effect on $\mathrm{C} 1$ : [C1 C2 C3 } \\
\hline & $\begin{array}{l}\text { C1 closing } \\
\text { movement } \\
\text { duration }\end{array}$ & $\begin{array}{c}\text { C1 closing } \\
\text { movement time-to- } \\
\text { peak-velocity }\end{array}$ & $\begin{array}{l}\text { C1 opening } \\
\text { movement } \\
\text { duration }\end{array}$ & $\begin{array}{c}\text { C1 opening } \\
\text { movement } \\
\text { time-to- } \\
\text { peak-velocity }\end{array}$ \\
\hline \multirow{3}{*}{$\begin{array}{c}\text { Subject A } \\
n=24\end{array}$} & $t=3.584, p=0.0017$ & $t=3.071, p=0.0056$ & n.s. & n.s. \\
\hline & Control: $70(7)$ & Control: $37(5)$ & Control: 149 (21) & Control: 97 (19) \\
\hline & Test: $151(78)$ & Test: $92(61)$ & Test: $131(35)$ & Test: $96(31)$ \\
\hline \multirow{4}{*}{$\begin{array}{c}\text { Subject D } \\
n=18\end{array}$} & $t=5.857, p<0.0001$ & $t=4.940, p=0.0001$ & $t=3.720, p=0.0019$ & $t=3.927$ \\
\hline & Control: $92(7)$ & Control: $49(6)$ & Control: 107 (5) & $p=0.0012$ \\
\hline & Test: 225 (76) & Test: 125 (51) & Test: $137(26)$ & Control: $63(6)$ \\
\hline & & & & Test: 94 (25) \\
\hline \multirow{3}{*}{$\begin{array}{c}\text { Subject E } \\
n=22\end{array}$} & $t=5.067, p<0.0001$ & $t=5.369, p<0.0001$ & n.s. & n.s. \\
\hline & Control: 65 (11) & Control: 29 (4) & Control: 122 (6) & Control: 73 (7) \\
\hline & Test: 98 (18) & Test: 51 (13) & Test: $118(5)$ & Test: 75 (3) \\
\hline \multirow{3}{*}{$\begin{array}{c}\text { Subject J } \\
n=20\end{array}$} & $t=2.448, p=0.0248$ & $t=2.964, p=0.0083$ & $t=4.063, p=0.0007$ & $t=4.194, p=0.0005$ \\
\hline & Control: 91 (18) & Control: $31(8)$ & Control: 120 (10) & Control: $85(8)$ \\
\hline & Test: 174 (100) & Test: 104 (73) & Test: 167 (34) & Test: 135 (35) \\
\hline
\end{tabular}

pre- and post-tonic accent exists. In the postboundary condition, all subjects place a very small accent on "dodo knocking" in both the control and the postboundary test sentences. Regarding the postboundary test sentence, for two speakers (A and $\mathrm{J}$ ), there were differences in the accent size of F0 perturbation in the postboundary and control conditions, although, as noted above, the control condition also had a posttonic accent. For the other two speakers, these differences do not occur. Therefore, it is reasonable to conclude that the consistency, observed below across subject results, reflects the prosodic boundary effects, not any accentual differences.

We will start with a discussion of the preboundary effects, and follow that with a discussion of the postboundary effects, with temporal effects considered first and spatial effects following.

\section{A. Preboundary temporal scope of effect: C3 C2 C1] (N D D])}

$T$-test results for the preboundary scope of temporal effects on $\mathrm{C} 1$ are shown in Table II; there were no significant results for preboundary $\mathrm{C} 2$ and $\mathrm{C} 3$ (these means are included in the Appendix). All subjects show a significant and large effect of a phrase boundary on the duration of opening movement of the preboundary $\mathrm{C} 1$ consonant, which was longer in the test than control utterance. Two subjects (A and J) show a significant effect in their time-to-peak-velocity for $\mathrm{C} 1$ opening movement in that reaching peak velocity takes longer in the test than in the control condition. One subject (D) shows a significant effect on early movement intervals, in that $\mathrm{C} 1$ closing movement and $\mathrm{C} 1$ closing movement time-to-peak-velocity are longer in the test than in the control condition.

\section{B. Postboundary temporal scope of effect: [C1 C2 C3 ([D D N)}

In the postboundary direction, all subjects have longer closing durations and time-to-peak-velocities for $\mathrm{C} 1$ in the test condition as compared to the control condition. $T$-test results are given in Table III. For two subjects (D and J), C1 opening movement also shows longer durations and time-topeak-velocity.

However, an interesting and unexpected result was observed for $\mathrm{C} 2$ and $\mathrm{C} 3$, and this result was obtained across subjects for both the closing and opening movements of the postboundary $\mathrm{C} 2$ and $\mathrm{C} 3$. (Recall that while $\mathrm{C} 3$ opening movement time-to-peak-velocity was measured, C3 opening movement duration was not). Subjects show shorter durations for these consonants in the test condition compared to the control no-boundary condition. These effects were quite uniformly significant (see Table IV).

In sum, there is a significant lengthening effect on $\mathrm{C} 1$ closing and (for some subjects) opening movement, and a significant shortening effect for $\mathrm{C} 2$ and $\mathrm{C} 3$. It is important to note that while this shortening is compensatory in direction (relative to the preceding lengthening), the shortening was not nearly as large in magnitude as the phrase-initial lengthening.

\section{Scope of spatial effects}

The preboundary spatial effects are inconsistent across subjects and across consonants. Means are given in Table V and the Appendix and significant results detailed below. While all speakers have temporally longer $\mathrm{C} 1$ opening movement and two had longer time-to-peak-velocities, there are no consistent preboundary effects in the spatial domain. While three subjects have a significant effect on preboundary $\mathrm{C} 1$ opening displacement, some have larger movements 
TABLE IV. Postboundary temporal effects on C2 and C3 $t$-test results and means (SD) (ms). NB: These are all shortening effects in direction for the test condition. The reported $n$ is the total number of tokens in the test plus the control conditions.

\begin{tabular}{|c|c|c|c|c|}
\hline \multicolumn{5}{|c|}{ Postboundary temporal scope of effect on $\mathrm{C} 2$ : [C1 C2 C3 } \\
\hline & $\begin{array}{l}\text { C2 closing } \\
\text { movement } \\
\text { duration }\end{array}$ & $\begin{array}{c}\text { C2 closing } \\
\text { movement time-to- } \\
\text { peak-velocity }\end{array}$ & $\begin{array}{l}\mathrm{C} 2 \text { opening } \\
\text { movement } \\
\text { duration }\end{array}$ & $\begin{array}{c}\text { C2 opening } \\
\text { movement time-to- } \\
\text { peak-velocity }\end{array}$ \\
\hline \multirow{3}{*}{$\begin{array}{c}\text { Subject A } \\
n=24\end{array}$} & $t=4.229, p=0.0003$ & $t=7.317, p<0.0001$ & $t=4.095, p=0.0005$ & n.s. \\
\hline & Control: $76(5)$ & Control: 45 (4) & Control: 86 (13) & Control: 31 (3) \\
\hline & Test: 68 (4) & Test: $35(2)$ & Test: $64(13)$ & Test: $31(6)$ \\
\hline \multirow{3}{*}{$\begin{array}{c}\text { Subject D } \\
n=18\end{array}$} & $t=4.283, p=0.0006$ & $t=3.908, p=0.0013$ & $t=6.494, p<0.0001$ & $t=3.599, p=0.0024$ \\
\hline & Control: 98 (7) & Control: $56(7)$ & Control: $82(6)$ & Control: $45(8)$ \\
\hline & Test: $84(8)$ & Test: $44(6)$ & Test: $67(3)$ & Test: $34(5)$ \\
\hline \multirow{3}{*}{$\begin{array}{c}\text { Subject E } \\
n=22\end{array}$} & $t=3.551, p=0.002$ & $t=3.691, p=0.0014$ & $t=8.011, p<0.0001$ & $t=4.58, p=0.0002$ \\
\hline & Control: 88 (7) & Control: 55 (9) & Control: 96 (10) & Control: 40 (5) \\
\hline & Test: $80(4)$ & Test: $45(5)$ & Test: $65(9)$ & Test: $32(3)$ \\
\hline \multirow{5}{*}{$\begin{array}{c}\text { Subject J } \\
n=20\end{array}$} & $t=2.240, p=0.0379$ & $t=3.176, p=0.0052$ & $t=6.484, p<0.0001$ & $t=7.131, p<0.0001$ \\
\hline & Control: 69 (2) & Control: $36(2)$ & Control: $62(8)$ & Control: $32(3)$ \\
\hline & Test: $65(5)$ & Test: $33(3)$ & Test: $40(6)$ & Test: $21(4)$ \\
\hline & Postboun & ry temporal scope of e & ect on $\mathrm{C} 3$ : [C1 C2 C3 & \\
\hline & $\begin{array}{l}\text { C3 closing } \\
\text { movement } \\
\text { duration }\end{array}$ & $\begin{array}{l}\text { C3 closing } \\
\text { movement time-to- } \\
\text { peak-velocity }\end{array}$ & & $\begin{array}{l}\text { C3 opening } \\
\text { movement time-to- } \\
\text { peak-velocity }\end{array}$ \\
\hline \multirow{3}{*}{$\begin{array}{c}\text { Subject A } \\
n=24\end{array}$} & $t=3.501, p=0.002$ & $t=4.357, p=0.0003$ & & n.s. \\
\hline & Control: 84 (7) & Control: 47 (6) & & Control: 80 (7) \\
\hline & Test: $74(7)$ & Test: 37 (4) & & Test: 76 (14) \\
\hline \multirow{3}{*}{$\begin{array}{c}\text { Subject D } \\
n=18\end{array}$} & $t=4.233, p=0.0006$ & n.s. & & $t=2.473, p=0.025$ \\
\hline & Control: $90(7)$ & Control: 40 (6) & & Control: 54 (5) \\
\hline & Test: 70 (13) & Test: 39 (2) & & Test: 49 (4) \\
\hline \multirow{3}{*}{$\begin{array}{c}\text { Subject E } \\
n=22\end{array}$} & $t=6.279, p<0.0001$ & $t=4.220, p=0.0004$ & & $t=3.606, p=0.0018$ \\
\hline & Control: 91 (6) & Control: 50 (9) & & Control: $73(5)$ \\
\hline & Test: 77 (4) & Test: 37 (3) & & Test: 65 (6) \\
\hline \multirow{3}{*}{$\begin{array}{c}\text { Subject J } \\
n=20\end{array}$} & $t=5.348, p<0.0001$ & $t=2.107, p=0.0494$ & & n.s. \\
\hline & Control: 115 (18) & Control: $38(7)$ & & Control: 62 (16) \\
\hline & Test: 81 (9) & Test: 33 (3) & & Test: 54 (3) \\
\hline
\end{tabular}

(Subject D, $t=4.8, p=0.0001, n=21)$ and some smaller (Subject A $t=5.154, p<0.0001, n=24$; Subject E, $t=5.035, p$ $<0.0001, n=23)$. With regard to $\mathrm{C} 1$ closing, though one subject (D) has a longer preboundary $\mathrm{C} 1$ closing duration, no spatial effect is observed for her; only one subject $(\mathrm{J})$ has an effect on $\mathrm{C} 1$ closing movement displacement $(t=2.992, p$ $=0.0086, n=18)$, such that the boundary condition is smaller than control. Subject J also shows smaller displacements in the boundary condition for $\mathrm{C} 2$ opening $(t=3.432, p$ $=0.0034, n=18)$ and closing movements $(t=2.896, p$ $=0.0105, n=18$ ). Two subjects (A and J) have an effect on C3 opening (A: $t=2.137, p=0.044, n=24 ; \mathrm{J}: t=2.403, p$ $=0.0287, n=18$ ) in opposite directions, $\mathrm{J}$ again with smaller displacements in the boundary condition. Finally, Subject E shows a significant effect on $\mathrm{C} 3$ closing movement displacement $(t=2.120, p=0.0461, n=23)$.

For extremum position, two subjects (E and J) show a significant effect for $\mathrm{C} 2$ (E $t=3.965, p=0.0007, n=23 ; \mathrm{J} t$ $=2.367, p=0.0309, n=18)$ and one subject $(\mathrm{E})$ for $\mathrm{C} 3(t$
$=3.556, p=0.0019, n=23)$. In all instances, the test condition showed less extreme positions than the control condition.

In contrast, postboundary spatial effects are more consistent and pattern consistently with the observed temporal effects. Results are shown in Table V. All subjects show larger displacements for $\mathrm{C} 1$ closing movement in the boundary condition. Note that this was the position for which all subjects show postboundary lengthening. For $\mathrm{C} 1$ opening movement, one subject has a slightly larger displacement in the test condition; and for C2 displacement, Subject E shows more displacement and Subject J shows less displacement in the test condition. A consistent pattern of smaller displacements was obtained for $\mathrm{C} 2$ opening movement and $\mathrm{C} 3$ closing movement for all subjects' boundary condition. Note that these were the two positions that also show consistent compensatory temporal shortening.

We note that postboundary $\mathrm{C} 1$ displacement differences are driven almost entirely by differences in onset position of the movement; namely for $\mathrm{C} 1$, the tongue tip started at a 


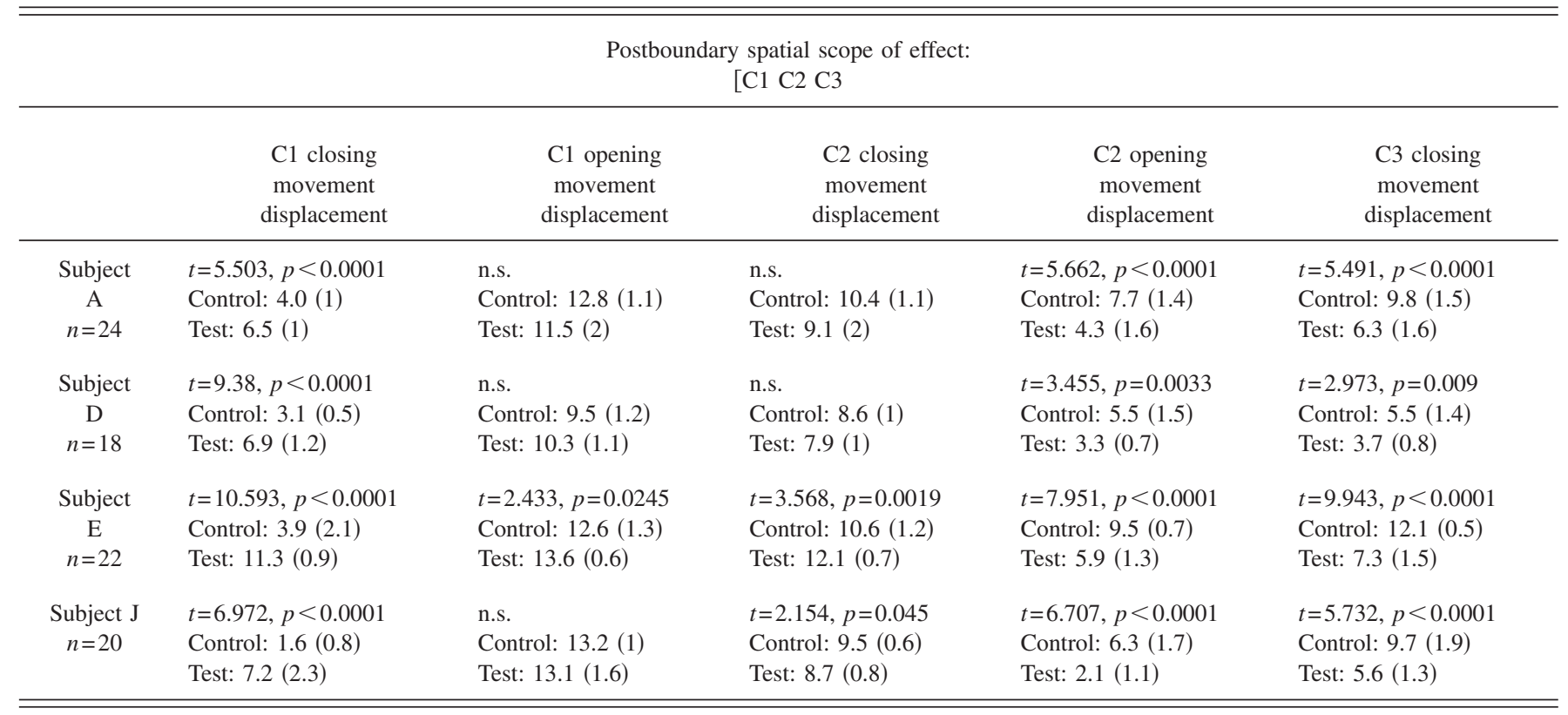

lower position. (That is, for all subjects, there is a significant effect for $\mathrm{C} 1$ closing movement in that the test condition had lower onset positions.) For C2 and C3 displacement changes, however, both onset and extremum positions change differentially_contributing to individuals' displacement effects. Subject D had a postboundary effect on C2 extremum position $(t=2.918, p=0.0101, n=18)$ and Subject $\mathrm{E}$ had an effect on C3 extremum position $(t=3.387, p=0.0029, n=22)$, with the direction of the effect opposite for each subject. As for onset position, Subject E had an effect on C2 onset position, and for C3 all subjects except D showed such an effect-but the direction of the effect varied.

\section{Summary of results}

\section{Summary of preboundary effect}

The most salient preboundary results are the temporal effects. All subjects have longer C1 opening movement durations, and two subjects have a longer time-to-peak-velocity as well in this position. One subject also has longer duration and time-to-peak-velocity for the $\mathrm{C} 1$ closing movement. Recall that this closing movement was for the consonantal onset of the preboundary syllable, i.e., that a vowel removes this consonant from immediate adjacency to the phrase edge.

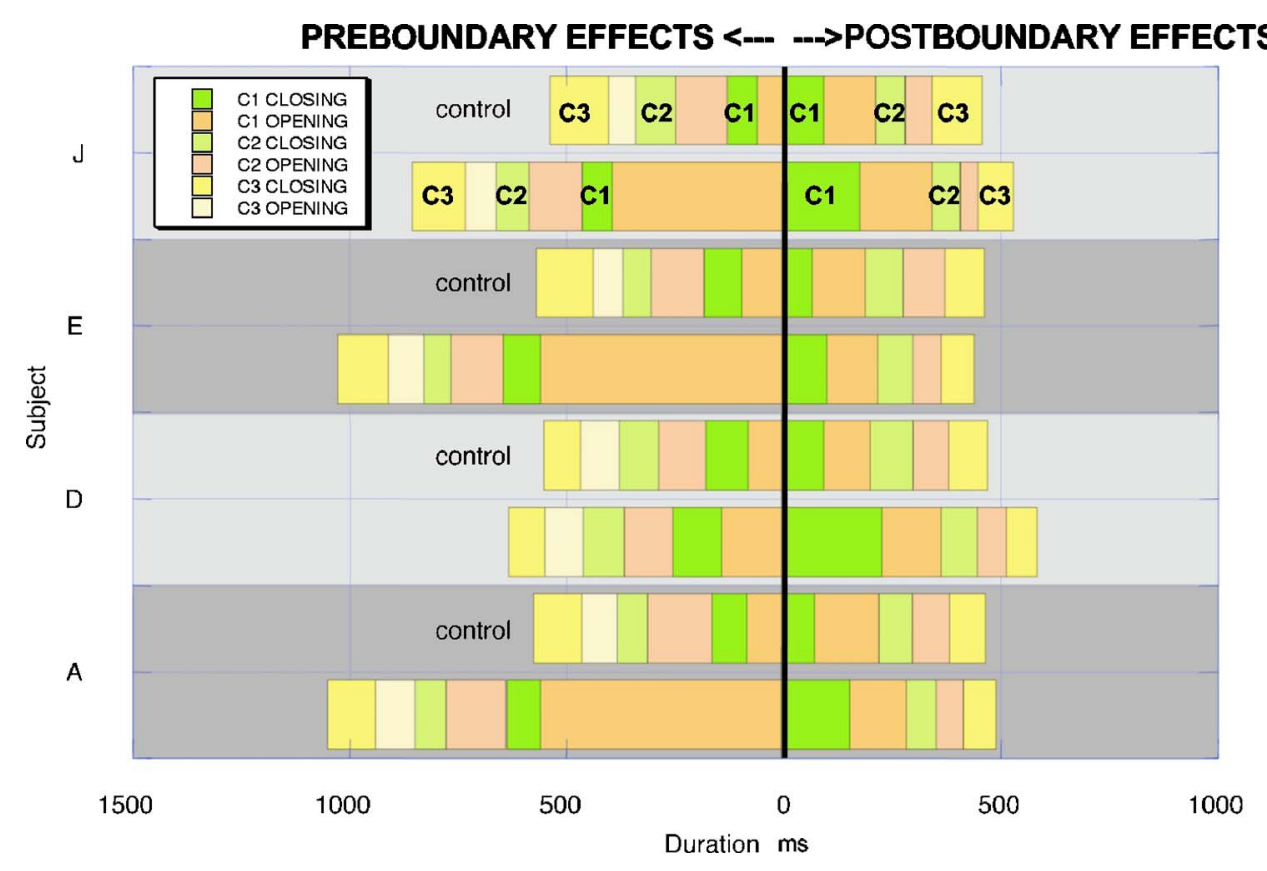

FIG. 4. (Color online) Consonant closing movement and opening movement duration results. The top bar for each speaker's pair is control and the bottom bar is test. (The bold line at center is merely a graphical convenience to separate results in the two conditions.) 
The spatial effects are inconsistent across subjects and conditions. For the $\mathrm{C} 1$ opening movement, there are no consistent spatial effects to accompany the temporal effectssome subjects have larger $\mathrm{C} 1$ opening movements and some smaller. For the speaker who had a longer $\mathrm{C} 1$ closing movement duration, no spatial effect was observed.

\section{Summary of postboundary effect}

The temporal effects show a clear postboundary pattern. For $\mathrm{C} 1$, there was a lengthening effect. The $\mathrm{C} 1$ closing movement has a longer duration and longer time-to-peakvelocity for all subjects. The $\mathrm{C} 1$ opening movement shows longer opening movement duration and longer time-to-peakvelocity for two subjects.

However, the closing movements and the opening movement examined for $\mathrm{C} 2$ and $\mathrm{C} 3$ show a shortening after $\mathrm{C} 1$ lengthening. All subjects show a shortening in duration and time-to-peak-velocity for the $\mathrm{C} 2$ closing movement. For the C2 opening movement, all subjects show shortening in duration, and three subjects show shortening of time-to-peakvelocity. For the C3 closing movement, all subjects show shorter duration, and three subjects show shorter time-topeak-velocity. For the $\mathrm{C} 3$ opening movement, time-to-peakvelocity is shorter for two subjects. Despite its compensatory direction, the degree of shortening is quite small; much smaller than previous lengthening.

Overall, the postboundary spatial effects consistently correspond to the temporal effects. That is, for $\mathrm{C} 1$ closing movement, all subjects show a larger displacement in the boundary condition. For C2 opening movement and for $\mathrm{C} 3$ closing movement, all subjects show smaller displacement in the boundary condition.

A summary of the temporal results that indicates the scope of boundary related temporal lengthening is shown in Fig. 4. (The bold line down the center of Fig. 4 is presented solely for the graphical ease of placing the preboundary and postboundary results on a single graph, i.e., it has no theoretical or methodological significance.)

\section{DISCUSSION}

The main findings of the experiment are: (a) Preboundary temporal effects, (b) postboundary temporal and spatial effects, (c) followed further into the phrase by postboundary compensatory shortening effects (accompanied by smaller displacements).

The prosodic $\pi$-gesture model (Byrd and Saltzman, 2003) predicts that activation slowing of articulatory gestures will increase as the $\pi$-gesture's activation increases and wane as the $\pi$-gesture's activation decreases. Our results show a strong local lengthening of the opening movement of the $\mathrm{C} 1$ preboundary consonant (in the $\mathrm{CV}$ syllable preceding the boundary) and of the closing movement of the $\mathrm{C} 1$ postboundary consonant. One subject (D) also shows lengthening of the closing movement of the preboundary $\mathrm{C} 1$ consonant, and, importantly, this effect is smaller in magnitude than the effect on the phrase-final $\mathrm{C} 1$ opening (a change of $15 \mathrm{~ms}$ for closing movement versus $61 \mathrm{~ms}$ for opening movement). Postboundary, two subjects also have effects on the opening movement of $\mathrm{C} 1$-again, the effect is smaller than that shown for the immediately phrase-initial C1 closing (Subject D: Closing movement, the mean difference is $133 \mathrm{~ms}$ versus opening movement, $30 \mathrm{~ms}$; Subject J closing movement, the mean difference is $91 \mathrm{~ms}$ versus opening movement, $48 \mathrm{~ms}$ ). Thus, for the subjects for whom the boundary effect extends further than the boundary-adjacent movement-further leftward than $\mathrm{C} 1$ release preboundary, and further rightward than $\mathrm{C} 1$ closing postboundary - the effect of the boundary decreases with distance from the phrase edge (i.e., for Subject D, preboundary, and for Subjects D and J, postboundary). These decreasing effects are compatible with the $\pi$-gesture model in which the activation of the prosodic gesture extends over an interval, waxing and waning in strength.

The phrase-final and initial lengthening effects are roughly symmetrical, though the time-to-peak-velocity is affected only for two subjects preboundary; but for all four subjects, postboundary-presumably because the postboundary consonant is immediately at the phrase edge, unlike the preboundary syllable-onset consonant. Spatial effects are consistent for the postboundary articulations and pattern with the temporal effects, but this is not the case in the preboundary direction.

Particularly interesting results are the compensatory effects shown postboundary for $\mathrm{C} 2$ and $\mathrm{C} 3$, which to our knowledge have not been reported previously. It should be noted that they are much smaller than the lengthening effects, so are not "literally" compensatory. It is our view that the compensatory shortening is not a direct effect of the $\pi$-gesture; in other words, it is not a planned prosodic shortening that is occurring. Rather, it appears that, following the prosodic lengthening, there is an attraction of the constriction gestures back in the direction of the prosodically unmodified or unperturbed timing. If the prosodic lengthening were not compensated for at all, the effect of a phrase boundary would be to prolong the time of the utterance for precisely the duration of the local phrasal lengthening; this is unlikely to be the case. Studies on focal accent have suggested that while local gesture duration does affect global utterance duration, it does not prolong the utterance duration for the whole amount of the prosodic lengthening (Weismer and Ingrisano, 1979; consider also Lindblom and Rapp, 1973; Saltzman et al., 2000). The compensatory shortening shown after a phrasal lengthening in our results indicates that the timing that would have been expected without prosodic warping is partially restored.

We conclude from the results of this articulatory kinematic experiment that the temporal prosodic effects on articulation are near the juncture, though not confined to the articulations immediately preceding or following the juncture; and they wax and wane in magnitude, both phrase finally and phrase initially. We further suggest that local gesture-to-gesture speech timing is sensitive to prosodic events, even downstream of those prosodic modifications. 
TABLE A1. Means (SD) (ms) for preboundary C2 and C3 durations (no significant differences exist).

\begin{tabular}{|c|c|c|c|c|c|c|c|c|}
\hline $\begin{array}{c}n \text { includes } \\
\text { test }+ \text { control }\end{array}$ & $\begin{array}{l}\text { C2 closing } \\
\text { movement } \\
\text { duration }\end{array}$ & $\begin{array}{c}\text { C2 closing } \\
\text { movement } \\
\text { time-to-peak- } \\
\text { velocity }\end{array}$ & $\begin{array}{c}\text { C2 opening } \\
\text { movement } \\
\text { duration }\end{array}$ & $\begin{array}{c}\text { C2 opening } \\
\text { movement } \\
\text { time-to-peak- } \\
\text { velocity }\end{array}$ & $\begin{array}{c}\text { C3 closing } \\
\text { movement } \\
\text { duration }\end{array}$ & $\begin{array}{c}\text { C3 closing } \\
\text { movement } \\
\text { time-to-peak- } \\
\text { velocity }\end{array}$ & $\begin{array}{c}\text { C3 opening } \\
\text { movement } \\
\text { duration }\end{array}$ & $\begin{array}{c}\text { C3 opening } \\
\text { movement } \\
\text { time-to-peak- } \\
\text { velocity }\end{array}$ \\
\hline $\begin{array}{c}\text { Subject A } \\
n=24\end{array}$ & $\begin{array}{l}\text { Control: } 70(7) \\
\text { Test: } 72(8)\end{array}$ & $\begin{array}{l}\text { Control: } 37(5) \\
\text { Test: } 38 \text { (5) }\end{array}$ & $\begin{array}{l}\text { Control: } 149 \\
(21) \\
\text { Test: } 136(18)\end{array}$ & $\begin{array}{l}\text { Control: } 97 \\
(19) \\
\text { Test: } 90(15)\end{array}$ & $\begin{array}{l}\text { Control: } 111 \\
(30) \\
\text { Test: } 110(34)\end{array}$ & $\begin{array}{l}\text { Control: } 40(5) \\
\text { Test: } 41(5)\end{array}$ & $\begin{array}{l}\text { Control: } 82 \\
(25) \\
\text { Test: } 92(24)\end{array}$ & $\begin{array}{l}\text { Control: } 80(23) \\
\text { Test: } 88 \text { (19) }\end{array}$ \\
\hline $\begin{array}{c}\text { Subject D } \\
n=21\end{array}$ & $\begin{array}{l}\text { Control: } 92(8) \\
\text { Test: } 95(9)\end{array}$ & $\begin{array}{l}\text { Control: } 49 \text { (6) } \\
\text { Test: } 45 \text { (7) }\end{array}$ & $\begin{array}{l}\text { Control: } \\
107(5) \\
\text { Test:112 (10) }\end{array}$ & $\begin{array}{l}\text { Control: } 63(6) \\
\text { Test: } 63(6)\end{array}$ & $\begin{array}{l}\text { Control: } 82(6) \\
\text { Test: } 83(7)\end{array}$ & $\begin{array}{l}\text { Control: } 41(4) \\
\text { Test: } 43(6)\end{array}$ & $\begin{array}{l}\text { Control: } 90(9) \\
\text { Test: } 87 \text { (8) }\end{array}$ & $\begin{array}{l}\text { Control: } 90(9) \\
\text { Test: } 87(8)\end{array}$ \\
\hline $\begin{array}{c}\text { Subject E } \\
n=23\end{array}$ & $\begin{array}{l}\text { Control: } 65 \\
(11) \\
\text { Test: } 62(3)\end{array}$ & $\begin{array}{l}\text { Control: } 29(4) \\
\text { Test: } 30 \text { (3) }\end{array}$ & $\begin{array}{l}\text { Control: } 122 \\
(6) \\
\text { Test: } 120(4)\end{array}$ & $\begin{array}{l}\text { Control: } 73(7) \\
\text { Test: } 69(5)\end{array}$ & $\begin{array}{l}\text { Control: } 129 \\
\text { (19) } \\
\text { Test: } 117 \text { (32) }\end{array}$ & $\begin{array}{l}\text { Control: } 47(3) \\
\text { Test: } 50(13)\end{array}$ & $\begin{array}{l}\text { Control: } 69 \\
(14) \\
\text { Test: } 81 \text { (24) }\end{array}$ & $\begin{array}{l}\text { Control: } 66(12) \\
\text { Test: } 73(14)\end{array}$ \\
\hline $\begin{array}{c}\text { Subject J } \\
n=18\end{array}$ & $\begin{array}{l}\text { Control: } 91 \\
(18) \\
\text { Test: } 76 \text { (18) }\end{array}$ & $\begin{array}{l}\text { Control: } 31 \text { (9) } \\
\text { Test: } 47 \text { (24) }\end{array}$ & $\begin{array}{l}\text { Control: } 120 \\
(10) \\
\text { Test: } 120 \text { (6) }\end{array}$ & $\begin{array}{l}\text { Control: } 85(8) \\
\text { Test: } 84(5)\end{array}$ & $\begin{array}{l}\text { Control: } 133 \\
(33) \\
\text { Test: } 122(34)\end{array}$ & $\begin{array}{l}\text { Control: } 37(8) \\
\text { Test: } 38 \text { (4) }\end{array}$ & $\begin{array}{l}\text { Control: } 64 \\
(26) \\
\text { Test: } 71 \text { (28) }\end{array}$ & $\begin{array}{l}\text { Control: } 62(21) \\
\text { Test: } 67(22)\end{array}$ \\
\hline
\end{tabular}

TABLE A2. Means (SD) for preboundary displacement $(\mathrm{mm})\left({ }^{*}\right.$ indicates a significant difference as detailed in text).

\begin{tabular}{|c|c|c|c|c|c|c|}
\hline $\begin{array}{c}n \\
\text { includes } \\
\text { test+ } \\
\text { control }\end{array}$ & $\begin{array}{c}\text { C3 closing } \\
\text { movement } \\
\text { displacement }\end{array}$ & $\begin{array}{c}\text { C3 opening } \\
\text { movement } \\
\text { displacement }\end{array}$ & $\begin{array}{c}\text { C2 closing } \\
\text { movement } \\
\text { displacement }\end{array}$ & $\begin{array}{c}\text { C2 opening } \\
\text { movement } \\
\text { displacement }\end{array}$ & $\begin{array}{l}\text { C1 closing } \\
\text { movement } \\
\text { displacement }\end{array}$ & $\begin{array}{c}\text { C1 opening } \\
\text { movement } \\
\text { displacement }\end{array}$ \\
\hline Subject & Control: $3.8(0.7)$ & *Control: 2 (0.8) & Control: 4 (1.0) & Control: 12.8 (1.1) & Control: 10.4 (1.1) & ${ }^{*}$ Control: 7.7 (1.4) \\
\hline $\begin{array}{c}\mathrm{A} \\
n=24\end{array}$ & Test: $4.1(0.8)$ & Test: 2.8 (1.0) & Test: $4.4(0.9)$ & Test: $12.8(0.9)$ & Test: 10.5 (1.3) & Test: $4.4(1.7)$ \\
\hline $\begin{array}{c}\text { Subject } \\
\text { D } \\
n=21\end{array}$ & $\begin{array}{l}\text { Control: } 4.9(0.7) \\
\text { Test: } 4.9(0.8)\end{array}$ & $\begin{array}{l}\text { Control: } 3(0.5) \\
\text { Test: } 3(0.8)\end{array}$ & $\begin{array}{l}\text { Control: } 3.1(0.5) \\
\text { Test: } 3.3(0.5)\end{array}$ & $\begin{array}{l}\text { Control: } 9.5(1.2) \\
\text { Test: } 9.9(0.8)\end{array}$ & $\begin{array}{l}\text { Control: } 8.6(1.0) \\
\text { Test: } 9.4(1.4)\end{array}$ & $\begin{array}{l}{ }^{*} \text { Control: } 5.5(1.5) \\
\text { Test: } 9.0(1.8)\end{array}$ \\
\hline $\begin{array}{c}\text { Subject } \\
\text { E } \\
n=23\end{array}$ & $\begin{array}{l}\text { Control: } 9.7(0.7) \\
\text { Test: } 8.4(2.0)\end{array}$ & $\begin{array}{l}\text { Control: } 4.3(1.7) \\
\text { Test: } 3.9(1.3)\end{array}$ & $\begin{array}{l}\text { Control: } 3.9(2.1) \\
\text { Test: } 3.6(1.1)\end{array}$ & $\begin{array}{l}\text { Control: } 12.6(1.3) \\
\text { Test: } 12(1.1)\end{array}$ & $\begin{array}{l}\text { Control: } 10.6(1.2) \\
\text { Test: } 10.7(0.7)\end{array}$ & $\begin{array}{l}{ }^{*} \text { Control: } 9.5(0.7) \\
\text { Test: } 8.0(0.7)\end{array}$ \\
\hline $\begin{array}{c}\text { Subject } \\
\mathrm{J} \\
n=18\end{array}$ & $\begin{array}{l}\text { Control: } 3.2(0.9) \\
\text { Test: } 3.2(0.6)\end{array}$ & $\begin{array}{l}\text { *Control: } 1.2(0.5) \\
\text { Test: } 0.7(0.4)\end{array}$ & $\begin{array}{l}{ }^{*} \text { Control: } 1.6(0.8) \\
\text { Test: } 8(0.3)\end{array}$ & $\begin{array}{l}{ }^{*} \text { Control: } 13.2(1.0) \\
\text { Test: } 11.7(0.8)\end{array}$ & $\begin{array}{l}{ }^{*} \text { Control: } 9.4(0.6) \\
\text { Test: } 8.1(1.2)\end{array}$ & $\begin{array}{l}\text { Control: } 6.3(1.7) \\
\text { Test: } 4.6(2.7)\end{array}$ \\
\hline
\end{tabular}

TABLE A3. Means (SD) for extremum position ( $\mathrm{mm})\left({ }^{*}\right.$ indicates a significant difference). Negative numbers refer to positions below the occlusal plane.

\begin{tabular}{|c|c|c|c|c|c|c|}
\hline \multicolumn{4}{|c|}{ Preboundary } & \multicolumn{3}{|c|}{ Postboundary } \\
\hline $\begin{array}{c}n \text { includes } \\
\text { test }+ \text { control }\end{array}$ & C3 extremum & C2 extremum & $\mathrm{C} 1$ extremum & $\begin{array}{c}\text { C1 } \\
\text { extremum }\end{array}$ & $\begin{array}{c}\mathrm{C} 2 \\
\text { extremum }\end{array}$ & $\begin{array}{c}\mathrm{C} 3 \\
\text { extremum }\end{array}$ \\
\hline Subject A & Control: $-2.3(0.4)$ & Control: $-4.0(5.0)$ & Control: $-2.7(0.4)$ & Control: $-0.4(0.5)$ & Control: $-2.7(0.4)$ & Control: $-0.6(0.7)$ \\
\hline$n=24$ & Test: $-2.1(0.8)$ & Test: $-0.5(0.5)$ & Test: $-2.8(0.9)$ & Test: $-0.6(0.7)$ & Test: $-3.0(0.7)$ & Test: $-1.0(0.5)$ \\
\hline Subject D & Control: 5.5 (0.8) & Control: $5.6(0.7)$ & Control: 4.7 (0.4) & Control: $5.6(0.7)$ & ${ }^{*}$ Control: 4.7 (0.1) & Control: 4.7 (0.6) \\
\hline $\begin{array}{l}n=21 \text { (prebound); } \\
n=18 \text { (postbound) }\end{array}$ & Test: $5.3(1.0)$ & Test: $5.6(0.9)$ & Test: $5.1(1.0)$ & Test: $6.3(0.9)$ & Test: $3.9(0.3)$ & Test: $4.3(0.6)$ \\
\hline Subject E & *Control: -5.089 (0.7) & ${ }^{*}$ Control: $-5.5(0.7)$ & Control: -7.6 (0.6) & Control: $-5.5(0.7)$ & Control: $-7.6(0.6)$ & ${ }^{*}$ Control: $-4.9(0.6)$ \\
\hline $\begin{array}{l}n=23 \text { (prebound); } \\
n=22 \text { (postbound) }\end{array}$ & Test: $-6.414(1.0)$ & Test: $-6.8(0.8)$ & Test: $-8.0(0.6)$ & Test: $-5.6(0.5)$ & Test: $-7.1(0.4)$ & Test: $-5.8(0.5)$ \\
\hline Subject J & Control: $-4.2(0.7)$ & ${ }^{*}$ Control: $-3.8(0.5)$ & Control: $-7.6(0.3)$ & Control: $-3.8(0.5)$ & Control: $-7.6(0.3)$ & Control: $-4.2(0.7)$ \\
\hline $\begin{array}{l}n=18 \text { (prebound); } \\
n=20 \text { (postbound })\end{array}$ & Test: $-4.4(0.3)$ & Test: $-4.3(0.2)$ & Test: $-7.9(1.0)$ & Test: $-3.7(1.1)$ & Test: $-8.1(1.1)$ & Test: $-4.6(0.5)$ \\
\hline
\end{tabular}




\section{ACKNOWLEDGMENTS}

The authors gratefully acknowledge the support of the NIH (Grant No. DC03172) and the assistance of Dr. James Mah, Elliot Saltzman and Shri Narayanan.

${ }^{1}$ It is interesting to speculate as to the accommodation of extremely long pauses, where in some sense the speech stream stops and restarts again, within the $\pi$-gesture framework. There are two (simultaneously viable) ways to view pauses within the $\pi$-gesture framework. First, one might view a pause as resulting from an extremely strong $\pi$-gesture, such that there is no qualitative difference between strong boundaries with and without a pause; a strong enough $\pi$-gesture simply slows articulation to an "effective" stop. It may be sensible in this regard to think about boundaries with pauses as having a flattened or plateaued $\pi$-gesture activation trajectory shape (Byrd and Saltzman 2003). A second possibility is to have overlapping phrase-final and phrase-initial $\pi$-gestures, but the model critically assumes these to have the same quality and nature of effect (Byrd and Saltzman 2003). In either case, a pause could be understood as a period during which planning of a gestural score for the upcoming utterance is occurring (see, Goldstein et al. 2006). (We thank Elliot Saltzman for helpful input on this matter.)

Beckman, M. E., and Edwards, J. (1992). "Intonational categories and the articulatory control of duration," in Speech Perception, Production and Linguistics Structure, edited by Y. Tohkura, E. Vatikiotis-Bateson, \& Y. Sagisaka (Ohmsha, Tokyo, Japan), pp. 359-375.

Beckman, M. E., and Elam, G. A. (1997). "Guidelines for ToBI labelling," version 3.0, unpublished available online 〈http://www.ling.ohio-state.edu/ $\sim$ tobi/ame_tobi/labelling_guide_v3.pdf $\rangle$.

Berkovits, R. (1993a). "Progressive utterance-final lengthening in syllables with final fricatives," Lang Speech 36, 89-98.

Berkovits, R. (1993b). "Utterance-final lengthening and the duration of final-stop closures," J. Phonetics 21, 479-489.

Berkovits, R. (1994). "Durational effects in final lengthening, gapping, and contrastive stress," Lang Speech 37, 237-250.

Browman, C. P., and Goldstein, L. (1992). "Articulatory phonology: An overview," Phonetica 49, 155-180.

Byrd, D. (2000). "Articulatory vowel lengthening and coordination at phrasal junctures," Phonetica 57, 3-16.

Byrd, D., Kaun, A., Narayanan, S., and Saltzman, E. (2000). "Phrasal signatures in articulation," in Papers in Laboratory Phonology V. Acquisition and the Lexicon, edited by M. B. Broe and J. B. Pierrehumbert (Cambridge University Press) pp. 70-87.

Byrd, D., Lee, S., Riggs, D., and Adams, J. (2005). "Interacting effects of syllable and phrase position on consonant articulation," J. Acoust. Soc. Am. 118, 3860-3873.

Byrd, D., and Saltzman, E. (1998). "Intragestural dynamics of multiple phrasal boundaries," J. Phonetics 26, 173-199.

Byrd, D., and Saltzman, E. (2003). "The elastic phrase: Modeling the dynamics of boundary-adjacent lengthening," J. Phonetics 31, 149-180.

Cambier-Langeveld, T. (1997). "The domain of final lengthening in the production of Dutch," in Linguistics in the Netherlands 1997, edited by J. Coerts and H. de Hoop (John Benjamins, Amsterdam), pp. 13-24.

Cho, T. (2004). "Prosodically conditioned strengthening and vowel-to-vowel coarticuation in English," J. Phonetics 32, 141-176.

Cho, T. (2006). "Manifestation of prosodic structure in articulation: Evidence from lip movement kinematics in English," in Laboratory Phonology 8: Varieties of Phonological Competence, edited by L. Goldstein (Walter De Gruyter Inc., New York).
Cho, T., and Keating, P. (2001). "Articulatory and acoustic studies on domain-initial strengthening in Korean," J. Phonetics 29, 155-190.

Cho, T., and Jun, S. A. (2000). "Domain-initial strengthening as enhancement of laryngeal features: Aerodynamic evidence from Korean," Chicago Linguistics Society 36, 31-44.

Edwards, J., Beckman, M. E., and Fletcher, J. (1991). "The articulatory kinematics of final lengthening," J. Acoust. Soc. Am. 89, 369-382.

Fougeron, C. (2001). "Articulatory properties of initial segments in several prosodic constituents in French," J. Phonetics 29, 109-135.

Fougeron, C., and Keating, P. (1997). "Articulatory strengthening at edges of prosodic domains," J. Acoust. Soc. Am. 101, 3728-3740.

Gendrot, C. (2005). "Acoustic, kinematic, and aerodynamic aspects of word-initial and word-final vowels in preboundary context in French." In ZAS: Zeitschrift für Sprachwissenschaft 40, 45-61

Goldstein, L, Byrd, D., and Saltzman, E. (2006). "The role of vocal tract gestural action units in understanding the evolution of phonology," in From Action to Language: The Mirror Neuron System, edited by M. Arbib (Cambridge University Press, Cambridge, UK).

Hacopian, N. (2003). "A three-way VOT contrast in final position: Data from Armenian,” J. Int. Phonetic Assoc. 33, 51-80.

Keating, P., Cho, T., Fougeron, C., and Hsu, C. (2004). "Domain-initial articulatory strengthening in four languages," in Phonetic Interpretation (Papers in Laboratory Phonology VI), edited by J. Local, R. Ogden, and R. Temple (Cambridge University Press), pp. 143-161.

Keating, P., Wright, R., and Zhang, J. (1999). "Word-level asymmetries in consonant articulation," UCLA Working Papers in Phonetics 97, 157-173. Klatt, D. (1976). "Linguistics uses of segmental duration in English: Acoustic and perceptual evidence," J. Acoust. Soc. Am. 59, 1208-1221.

Lindblom, B., and Rapp, K. (1973). "Some temporal regularities of spoken Swedish," PILUS (Papers from the Institute of Linguistics, University of Stockholm) 21, 1-59.

McClean, M. (1973). "Forward coarticulation of velar movement at marked junctural boundaries," J. Speech Hear. Res. 16, 286-296.

Oller, K. D. (1973). "The effect of position in utterance on speech segment duration in English," J. Acoust. Soc. Am. 54, 1235-1247.

Saltzman, E., Löfqvist, A., and Mitra, S. (2000). "'Glue' and 'clocks': Intergestural cohesion and global timing," in Papers in Laboratory Phonology V, edited by M. B. Broe and J. B. Pierrehumbert (Cambridge University Press, Cambridge), pp. 88-101.

Saltzman, E. L., and Munhall, K. G. (1989). "A dynamical approach to gestural patterning in speech production," Ecological Psychol. 1, 333382.

Shattuck-Hufnagel, S., and Turk, A. (1998). "The domain of phrase-final lengthening in English," The Sound of the Future: A Global View of Acoustics in the 21st Century, Proceedings 16th International Congress on Acoustics and 135th Meeting Acoustical Society of America, 1235-1236.

Tabain, M. (2003). "Effects of prosodic boundary on /aC/ sequences: Articulatory results," J. Acoust. Soc. Am. 113, 2834-2849.

Tabain, M., and Perrier, P. (2005). "Articulation and acoustics of /i/ in preboundary position in French," J. Phonetics 33, 77-100.

Turk, A. E. (1999). "Structural influences on boundary-related lengthening in English," Proceedings of the XIVth International Congress of Phonetic Sciences, San Francisco, edited by J. J. Ohala, Y. Hasegawa, M. Ohala, D. Granville, and A. C. Bailey (The Regents of the University of California) 1, 237-240.

Weismer, G., and Ingrisano, D. (1979). "Phrase-level timing patterns in English: Effects of emphatic stress location and speaking rate," J. Speech Hear. Res. 22, 516-533.

Wightman, C. W., Shattuck-Hufnagel, S., Ostendorf, M., and Price, P. J. (1992). "Segmental durations in the vicinity of prosodic phrase boundaries," J. Acoust. Soc. Am. 91, 1707-1717. 